In the United Kingdom, the Royal College of Psychiatrists (1988) recommends that the training of general psychiatrists should include a placement in child and adolescent psychiatry with "exposure to a variety of theoretical orientations and exponents of different sorts of treatment including individual and family therapy".

It is not clear, however, to what extent trainees nationally have access to basic family therapy training and whether this experience receives appropriate emphasis. Given its wide application, is there not a case for further family therapy training during placements in general adult and old age psychiatry? As services expand within the community it is expedient that psychiatrists not only treat individuals but are also equipped to work with whole families.

\section{Conclusions}

The trainee in general psychiatry is most likely to encounter family therapy during a placement in child and adolescent psychiatry. A small and experienced clinical team is able to offer effective basic training, fostering an understanding of systems theory and the acquisition of important skills for working with families; since such skills are of increasing value to the general psychiatrist, we believe experience in family therapy should be an essential component in any training scheme.

\section{References}

CARTER, R. E. (1986) An evaluation of a partial training program in psychiatric residency on the later practice of marital and family therapy. American Journal of Family Therapy, 14, 145-153.

Guttman, H., Feldman, R. \& Bravermans, S. (1990) An integrated approach to family therapy training for psychiatric residents. Canadian Journal of Psychiatry, 35, 58-63.

Royal College of Psychiatrists Executive Committee of the Child and Adolescent Specialist Section (1988) Guidelines for the training of general psychiatrists in child and adolescent psychiatry. Bulletin of the Royal College of Psychiatrists, 12, 391-392.

\title{
Joint RCPsych/AUTP Workshop on Psychiatry in the Undergraduate Medical Curriculum
}

A joint RCPsych/AUTP Workshop on Psychiatry in the Undergraduate Medical Curriculum will be held from 1.30 p.m. to 5.00 p.m. on Monday 25 January 1993 at the Society of Chemical Industry, 14/15 Belgrave Square, London SW 1 .

Speakers will include Professor David Shaw (GMC Education Committee), Professor Chris
Thompson, Dr Jan Scott and Dr Phillip Snashell (Sub-Dean, Charing Cross and Westminster Medical School).

Further details and an application form can be obtained from Mrs Jennifer Andrews, Education Department, Royal College of Psychiatrists, 17 Belgrave Square, London SW1X 8PG. 